\title{
Inventário cientista-prático de orientação profissional em psicologia: um estudo exploratório ${ }^{1}$
}

\author{
Luiz Fernando de Lara Campos², Elaine Cristina Catão e Cristiane Miwa Fujii \\ Universidade São Francisco
}

\begin{abstract}
Resumo
O objetivo do presente trabalho foi verificar a viabilidade da utilização do Inventário Cientista-Prático aplicado individualmente em estudantes de Psicologia de uma instituição particular paulista. A partir das respostas de 46 alunos do 40 ano de Psicologia, foi possível verificar a preferência por atividades clínicas tradicionais e a baixa atração por atividades de pesquisa e planejamento em Psicologia, o que demonstrou uma boa viabilidade do instrumento.

Palavras-chave: inventário cientista-prático; aconselhamento de carreira; formação em psicologia.
\end{abstract}

\section{Scientist-practioner inventory in professional counseling in psychology: an exploratory study}

\section{Summary}

The purpose ofthis study was to verify the viability of Scientist-Practitioner Inventory completed individually by students ofPsychology of a University from São Paulo State. Based on the answers of 46 students of 4th year of Psychology, it has been found that most students showed a preference for traditional clinical activities while research and planning activities attracted very few students. It showed a good discrimination viability of Scientist-Practitioner Inventory under prevailing Brazilian conditions.

Key-words: scientist-practitioner inventory; career counseling; training in psychology.

A escolha profissional é um dos principais momentos no desenvolvimento do adolescente, sendo que esta etapa é, muitas vezes, apenas uma primeira decisão no campo profissional, principalmente para os que atingem o grau universitário. Na maioria das profissões universitárias existem vários campos ou áreas de atuação, sendo este um segundo momento de escolha na formação universitária. Na Medicina, por exemplo, o aluno deve optar pela área de atuação, ou seja, em que especialidade irá fazer seu internato. Em outras profissões esta situação se repete, inclusive na Psicologia.

Por intermédio da escolha de uma profissão e do desenvolvimento de uma carreira, o indivíduo passa a se projetar na sociedade a que pertence como participante ativo desta. A escolha ocupacional torna-se ponto de identificação dentro da comunidade e qualifica o indivíduo perante esta (Catão, 1999). A profissão define um conjunto de características que pode variar em termos de ocupações, enquanto carreira envolve a seqüência de trabalhos de uma profissão. Passareli (1991) acrescenta ainda que, se a carreira constitui um processo de interação com a profissão, não há um único momento de escolha, mas sim uma sucessão de opções.

A escolha ocupacional é um conjunto de diversas contingências diferenciadas, relacionadas ao poder econômico, traços de personalidade ou desejo de satisfação pessoal (Martins, 1978), sendo

\footnotetext{
${ }^{1}$ Trabalho apresentado parcialmente no II Encontro de Iniciação Científica da PUC-Campinas.

2 Docente do Mestrado em Psicologia - Universidade São Francisco. Endereço para correspondência: Querubim Uriel, 162, apto. 32, Campinas-SP - CEP 13024-470.
} 
que em diversos momentos durante a vida o indivíduo toma decisões e resolve problemas relativos à escolha ocupacional (Holland, 1978).

Passareli (1991) afirma que o estudo detalhado das trajetórias profissionais é de grande relevância na obtenção de compreensão dos aspectos relacionados à escolha profissional. Este tipo de estudo permite visualizar o processo de decisão e seu confronto com a evolução posterior da carreira, de modo que a escolha profissional implica numa interação constante do indivíduo não só com a profissão em si, mas sim com um conjunto de fatores que engloba vários contextos: o econômico, o social, o cultural, o político e o psicológico.

Para Bastos (1997) as características que definem um profissional surgem de uma espécie diferenciada de relação que este estabelece com sua profissão, podendo ser classificada pelo seu alto grau de envolvimento, sentimentos de identidade, autonomia e adesão aos seus objetivos e valores.

A insatisfação com a profissão parece estar relacionada a diversos fatores, dentre os quais se destacam um certo sentimento de incongruência entre as características da profissão e os interesses pessoais, ou então, condições de trabalho que interfiram na vida pessoal ou familiar, ou ainda que restrinjam a liberdade e a criatividade do profissional (Teixeira e Gomes, 1998). Pode-se compreender os problemas relacionados à escolha ocupacional e ao planejamento de carreira como fatores que parecem ocasionar dificuldades no tocante à saúde mental (Osipow, 1990).

Na busca de soluções para os problemas de escolha e desenvolvimento profissional, o aconselhamento de carreira se desenvolveu como campo da Psicologia, principalmente como resposta a uma demanda de problemas sociais, particularmente relacionados à questão vocacional (Goodyear e Bates, 1992). Embora tenha sido influenciado por inúmeras propostas teóricas, a história do aconselhamento psicológico ainda reflete a influência de alguns movimentos sociais como o feminismo e o multi-culturalismo (Blustein, 1995), sendo que nas últimas décadas, vem ganhando consideravelmente mais espaço, além de periódicos científicos especializados (p.ex., The Counseling Psychologist, Journal of Counseling Psychology, Professional Psychology, Journal of Counseling and Development).

As pesquisas voltadas ao aconselhamento de carreira focalizam-se no estudo de variáveis que afetam o desenvolvimento de uma carreira, como mensurá-las e de que forma ajudar os clientes em suas carreiras. Uma larga parcela destas pesquisas concentra sua atenção no estudo da relação entre características pessoais, educação e desempenhos e preferências diretamente ligadas à ocupação em si (Healy, 1992), pois a satisfação e (ou) realização profissional serão determinadas pela congruência entre as características pessoais de cada sujeito e aquelas provenientes do ambiente de trabalho (Holland, 1978).

Na escolha do estudante de Psicologia a situação é a mesma, pois embora suas bases científicas estejam definidas (AP A, 1978), é na prática, na ação dos psicólogos, onde este trabalha, com quem e para que realiza tal trabalho é que se compreende a amplitude da sua atuação profissional.

De um modo geral, os alunos de Psicologia enfrentam pelo menos duas dificuldades durante seu curso. A primeira ocorre no momento de se optar por um referencial teórico, o qual servirá de base para o futuro exercício profissional. Esta situação talvez ocorra devido à grande desunião teórico-conceitual que caracteriza a Psicologia (Staats, 1987), demonstrada, por exemplo, na presença de mais de 400 linhas psicoterápicas (Feixas e Miró, 1993), as quais constituem um amplo 
leque de alternativas contraditórias e muitas vezes conflitantes.

No caso da Psicologia, como de todas as outras profissões, espera-se que durante os anos de graduação, o futuro profissional possa visualizar quais as condições e (ou) ambientes distintos em que seu trabalho pode ser realizado, obter informações apuradas acerca de sua futura ocupação, entrar em contato direto com a realidade da profissão escolhida e, assim, definir melhor seu âmbito de atuação, assim como as competências demandadas por esta ou aquela escolha.

A partir da regulamentação da profissão em 1962, ficou estabelecido que o curso superior destinado à formação do psicólogo teria a duração de cinco anos e deveria adequar-se na proposta do currículo mínimo (Guzzo e Wechsler, 1993). Este, por sua vez, está estruturado de forma a fornecer ao graduando informações sobre as várias abordagens psicológicas e as áreas de atuação, devendo, também, incluir estágios supervisionados nos vários níveis de formação, acrescentando sempre novas áreas de conhecimento e atuação do psicólogo (CFP, 1994).

Durante os anos de formação profissional, o graduando em Psicologia se depara com um leque de possibilidades variadas, dentre as quais, próximo à conclusão do curso, terá que optar 'por área de atuação e abordagem teórica, além de determinar a carreira a seguir e o início de sua prática profissional (Morato e cols., 1993). Para efetuar tais escolhas, necessitará, durante o curso, manter contato com matérias teóricas e atividades práticas que possibilitem perceber quais seus interesses e afinidades dentro do campo da Psicologia.

Os dados sobre o mercado de trabalho (CFP, 1988; CFP, 1994) apontam para o fato de que futuros profissionais com pretensão de atuarem como clínicos, principalmente em abordagem de base psicanalítica, enfrentaram vários obstáculos, devido à atual situação de saturação em que se encontra esta faixa do mercado, onde $80 \%$ dos psicólogos atuantes no Brasil concentram suas atividades. Este quadro demonstra que o estudante prestes a graduar-se em Psicologia, deveria ter como opções outras áreas de atuação, para uma tomada de decisão em relação à carreira profissional.

Dentre os vários aspectos que influenciam a formação do psicólogo, a identidade social parece ter forte influência, principalmente entre os próprios graduandos de Psicologia. Os dados levantados pelo CFP (1994) sugerem que estes acreditam que apenas será plenamente psicólogo aquele que realmente atuar na área clínica. Neste mesmo sentido, Freitas, Menezes e Louzada (1995) verificaram que as concepções sobre o profissional de Psicologia e sua atuação junto à comunidade privilegiam a prática clínica e (ou) psicoterapêutica, centralizam-se no atendimento individual e estão voltadas para a solução de problemas de natureza psicológica em geral, o que é confirmado pelos dados de Araújo e Murta (1995). De modo geral, os alunos de Psicologia demonstram dificuldades em reconhecer as áreas de atuação do psicólogo (Santos, 1992a), em saber quais os campos de trabalho e qual o papel a desenvolver em cada um destes campos. Ao ingressar no curso de Psicologia, o estudante caracteriza a profissão como tendo uma função social/assistencial (Pacheco, Mascarenhas e Magioli, 1998).

Campos e cols. (1996) constataram que a maioria dos estudantes acaba seguindo a tendência de seu curso, optando pela área e abordagem teórica mais comum e difundida entre as matérias que estudaram. Os autores relatam ainda que tal estrutura corresponde mais a um processo de doutrinação do que formação científica, não conduzindo à formação de um profissional coerente com as concepções hoje dominantes a respeito do saber e do fazer científicos. A falta de informação sobre as várias possibilidades de atuação do psicólogo acabam por favorecer a atuação clínica em 
detrimento das demais áreas (Campos 1989; 1994).

No tocante à área de Ensino e Pesquisa em Psicologia, dados levantados por Santos (1993) revelaram que as representações de alunos de Psicologia com referência a esta área restringem-se a situações de laboratório (análise experimental ou observação do comportamento), demonstrando, entre outras questões, que há falhas no conteúdo de disciplinas como Metodologia de Pesquisa, que não enfatizam a produção de conhecimento como sendo função importante na prática da Psicologia. Rodrigues, Gums e Reis (1998) demonstraram que apenas uma pequena parcela dos psicólogos brasileiros formados na última década reconhece a produção de conhecimento através da realização de pesquisas como sendo uma das tarefas necessárias e importantes de sua prática profissional. Soma-se a esta questão que, ao final do curso, o aluno apresenta várias e sérias dúvidas sobre o caráter científico da Psicologia (Santos, 1992b).

Há, entretanto, outras áreas que despontam no cenário nacional, como a Psicologia do Esporte e a Psicologia Jurídica (Bonfim, 1993), a Psicologia das Artes, a Psicologia Pastoral, a Psicologia da Saúde, a Psicologia da Computação, a Psicologia da Mídia e do Lazer (Pfromm Netto, 1992). Vale ressaltar que a maioria destas áreas é desbravada por muitos profissionais de outras áreas que não da Psicologia.

Entretanto, a despeito da gravidade da situação atual, a produção científica sobre a formação do psicólogo ainda é restrita, bem como a produção de instrumentos, técnicas e estratégias que auxiliem os alunos da área na escolha de áreas de atuação e até mesmo de referenciais teóricos.

Calejon (1996), ao revisar a literatura na área, relata que esse aspecto tem sido acentuado como fundamental, informando que, durante o curso, os estudantes de Psicologia experimentam sentimentos de incerteza quanto à escolha profissional e necessitam, portanto, de auxílio para superar tal conflito.

Nos Estados Unidos, Leong e Zachar $(1991,1993)$ reconheceram a necessidade de pesquisar a escolha de carreira entre alunos de Psicologia. Desenvolveram, então, o Scientist Practitioner Inventory (SPI), uma escala especialmente elaborada para a finalidade de levantar os interesses dos estudantes relativos a dois tipos de atividades em Psicologia: Ensino-Pesquisa e Psicologia Clínica.

O instrumento em questão contém 42 itens, destinados à deteç̧ão de características de personalidade e padrões de desenvolvimento que estejam associados a interesses práticos ou científicos, em específico (Leong e Zachar, 1993). Por meio de uma listagem de atividades exercidas por psicólogos (atividades terapêuticas, pesquisa, estatística, perícia em clínica, atividades de professor-editor-supervisor, vida acadêmica, aplicação e interpretação de testes), possivelmente experienciadas pelos estudantes durante o curso de Psicologia, busca-se levantar quais são as que despertam interesse e que estão de acordo com suas habilidades.

Leong e Zachar (1992) sustentam a hipótese de que há evidências claras sobre a existência de características específicas e distintas que discriminam entre profissionais cientistas e profissionais práticos. Uma vez que tais diferenças nunca haviam sido diretamente estudadas em alunos de Psicologia, procuraram então pesquisá-las através do SPI, que foi elaborado especialmente para esta finalidade.

Os autores mencionados basearam suas pesquisas no fato de que aspectos de personalidade sustentam as diferenças nos perfis destes dois tipos de profissionais e comprovaram que "graduandos com características de personalidade do tipo investigador-pesquisador, interessam-se por uma orientação científica e teórica objetiva, enquanto que graduando com características de 
personalidade do tipo social demonstraram aptidão para orientação prática e teórica subjetiva" (Leong e Zachar, 1992: 676).

Segundo Leong e Zachar (1993: 163), o Scientist Practitioner Inventory (SPI) "por ser um operacionalizador dessas dimensões da Psicologia (Pesquisa e Clínica), pode ser usado no aconselhamento de carreira, auxiliando estudantes a determinar a extensão de seu interesse". Salientam, ademais, que outros pesquisadores atestaram a eficiência do instrumento para auxiliar a instrução de estudantes de Psicologia sobre a extensão da profissão, promovendo uma reflexão mais exata sobre este aspecto.

Leong e Zachar (1993) testaram o instrumento criado por eles no contexto universitário norte-americano. No Brasil, Fuji e Campos (1997) realizaram uma pesquisa utilizando este instrumento e constataram que os estudantes brasileiros demonstram maior tendência em optar por atividades clínicas terapêuticas, baseadas no modelo médico, dados estes que vêm ao encontro do fato, já comprovado por vários estudos anteriores (p. ex., CFP, 1994), de que a maior concentração de psicólogos brasileiros atuantes está na área Clínica.

Entretanto, até o momento este instrumento não foi ainda testado no Brasil, de modo que face ao até aqui exposto, o objetivo do presente trabalho foi avaliar a viabilidade do Inventário CientistaPrático (Scientist Practitioner Inventory) na realidade brasileira e identificar a tendência de um grupo de alunos de Psicologia quanto à área de atuação.

\section{Método}

\section{Sujeitos}

Foram sujeitos, 46 alunos do quarto ano do curso de Psicologia de uma Instituição de Ensino Superior, particular, do Estado de S. Paulo, determinados acidentalmente.

Dos sujeitos, três foram do sexo masculino, 40 do feminino e três não identificaram seus sexos. A renda média familiar mensal dos sujeitos foi de mais de 20 salários-mínimos, mostrando nível sócioeconômico alto.

\section{Material}

Para coleta de dados foram utilizados dois instrumentos:

1. Questionário de identificação, contendo seis questões de identificação, abordando a caracterização do sujeito quanto a sexo e idade e nível sócioeconômico.

2. Inventário de orientação profissional cientista-prático (Scientist Practitioner Inventory), com 42 itens, sendo 13 relativos a atividades terapêuticas, 10 à pesquisa, cinco ao perito em clínica, quatro à estatística, quatro a professor-editor-supervisor, três a idéias acadêmicas, três a teste e interpretação. As respostas podem variar na escala entre 1 (Muito Pouco Interesse) até 5 (Muito Alto Interesse).

Este instrumento foi primeiramente traduzido do Inglês, sendo realizada posteriormente sua reversão, a fim de validar a tradução realizada.

\section{Procedimento}

Primeiramente foram identificados os sujeitos-possíveis, de modo que foram contactados 
para sua adesão ou não ao estudo.

Uma vez determinados os sujeitos, os instrumentos foram entregues aos sujeitos para que eles respondessem em suas residências e os retomassem no dia seguinte, sendo que o retorno efetivo ocorreu em até 30 dias. Foi garantido sigilo absoluto aos sujeitos.

\section{Resultados e discussão}

Para análise estatística, utilizou-se a prova do qui-quadrado, trabalhando-se com as freqüências percentuais como base da cálculo, ao nível de significância de 0,05 (Witter, 1996).

No tocante à subescala de "Atividades Terapêuticas", o item que obteve a maior média foi "Aprendizagem de novas estratégias para intervenção em problemas psicológicos" (4,89 pontos) sugerindo maior motivação para estudos e vivências relacionadas à aprendizagem de condutas clínicas (Tabela 1).

Tabela 1. Freqüência de respostas dos itens da subescala de Atividades Terapêuticas.

\begin{tabular}{l|c}
\hline \multicolumn{1}{c|}{ Item } & Média \\
\hline $\begin{array}{l}\text { Aprendizagem de novas estratégias para intervenção } \\
\text { em problemas psicológicos }\end{array}$ & 4,89 \\
\hline $\begin{array}{l}\text { Ajudar um cliente a entrar em contato com seus } \\
\text { sentimentos }\end{array}$ & 4,63 \\
\hline Fazer terapia para se tornar urna pessoa melhor & 4,34 \\
\hline Ler sobre novas propostas em psicoterapia & 4,30 \\
\hline $\begin{array}{l}\text { Assistir a urna conferência sobre técnicas } \\
\text { psicoterapêuticas }\end{array}$ & 4,30 \\
\hline $\begin{array}{l}\text { Conduzir urna sessão de psicoterapia com um cliente } \\
\text { individual }\end{array}$ & 4,28 \\
\hline Conduzir urna entrevista diagnóstica com um cliente & 4,19 \\
\hline Ler um livro de famoso psicoterapeuta & 4,13 \\
\hline Conduzir sessões de psicoterapia de grupo & 3,88 \\
\hline $\begin{array}{l}\text { Consultar outro psicólogo sobre aspectos particulares } \\
\text { de um cliente }\end{array}$ & 3,78 \\
\hline Conduzir terapia de casal ou familiar & 3,45 \\
\hline $\begin{array}{l}\text { Supervisionar a prática de estudantes em psicologia } \\
\text { clínica ou aconselhamento }\end{array}$ & 3,30 \\
\hline $\begin{array}{l}\text { Avaliar criticamente o sistema de triagem de clientes de } \\
\text { um serviço psicológico }\end{array}$ & 3,28 \\
\hline Média geral & 4,08 \\
\hline
\end{tabular}

No segundo posto ficou o item "Ajudar um cliente a entrar em contato com seus sentimentos" (4,63 pontos) já indicando possivelmente um dos motivos da busca pela área clínica.

É interessante notar que dos itens com médias mais baixas, três destacam-se por sugerir normas menos tradicionais na área clínica. O item "Conduzir terapia de casal ou familiar" (3,45 
pontos) sugere que o modelo ainda preferido pelos estudantes é voltado para atuação individual, representando um modelo de atuação antigo e tradicional, indo ao encontro do postulado por Feixas e Miró (1993) e por Freitas, Menezes e Louzada (1995).

Os outros dois aspectos menos pontuados "Supervisionar a prática de estudantes em Psicologia Clínica ou aconselhamento" (3,30 pontos) e "Avaliar criticamente o sistema de triagem de clientes de um serviço psicológico" (3,28 pontos) se referem a aspectos do treinamento e eficácia dos serviços de treinamento dos futuros psicólogos clínicos, o que parece confirmar a posição de Campos (1994) sobre a pouca perspectiva dos próprios alunos quanto à validade, pertinência e confiabilidade de seu treinamento e supervisão.

Na análise das respostas através do $X^{2}$, observou-se o valor de 1,38 , não suficiente para determinar a rejeição da hipótese nula $\left(X^{2}{ }_{\mathrm{c}}=21,03\right.$; n.g.1.=12; n.sig. $\left.=0,05\right)$, ou seja, nenhum dos itens foi significativamente mais pontuado do que outro.

Tabela 2. Freqüência de respostas dos itens da subescala de Atividades de Pesquisa.

\begin{tabular}{l|c}
\hline \multicolumn{1}{c|}{ Item } & Média \\
\hline Sugerir idéias sobre possíveis pesquisas com colegas & 3.10 \\
\hline Coletar dados de um projeto de pesquisa de estudantes & 3.00 \\
\hline Escrever artigos de pesquisa para a publicação & 2.86 \\
\hline Revisar a literatura sobre um tema específico em psicologia & 2.84 \\
\hline Elaborar um experimento para estudar um processo psicológico & 2.76 \\
\hline Trabalhar para um instituto de pesquisa & 2.76 \\
\hline Escrever um artigo comentando descobertas científicas & 2.71 \\
\hline Avaliar e conceder permissão para pesquisas & 2.45 \\
\hline Analisar dados oriundos de um experimento que você conduziu & 2.39 \\
\hline Revisar artigo de outros autores para revistas científicas & 2.08 \\
\hline Média geral & 2.38 \\
\hline
\end{tabular}

A Tabela 2 diz respeito à subescala de "Atividades de Pesquisa". O item de maior média foi sugerir idéias sobre possíveis pesquisas com colegas (3,10 pontos), indicando que os sujeitos possuem boas condições de percepção de temas ou problemas científicos. Outro item refere-se a coletar dados de um projeto de pesquisa de estudantes (3,00 pontos), que ao levar em consideração os dois itens de menor média, analisar dados oriundos de um experimento que você conduziu (2,39 pontos), e revisar artigo de outros autores para revistas científicas (2,08 pontos), sugere que os alunos de Psicologia evitam atividades que exigem análise crítica. É interessante notar que os itens que exigem produção científica e/ou revisão desta são menos pontuados, reforçando a pouca ênfase dada pelos estudantes de Psicologia a esta área. Tal posição confirma o que Rodrigues, Gums e Reis (1998) verificaram.

O X $\mathrm{X}^{2}$ observado nesta subescala (Tabela 2 ) foi de 1,16 , sendo que mais uma vez não se rejeitou a $H_{0}\left(X^{2}=16,92\right.$; n.g.1.=9; n.sig. $\left.=0,05\right)$, de modo que não se observou nenhum item mais pontuado do que os demais. 
Tabela 3. Freqüência de respostas dos itens da subescala de Atividades de Perito em Psicologia Clínica.

\begin{tabular}{l|c}
\hline \multicolumn{1}{c|}{ Item } & Média \\
\hline $\begin{array}{l}\text { Organizar um programa de tratamento em hospital } \\
\text { psiquiátrico }\end{array}$ & 3.47 \\
\hline $\begin{array}{l}\text { Delinear um novo método de tratamento para uma } \\
\text { instituição de saúde mental. }\end{array}$ & 3.34 \\
\hline $\begin{array}{l}\text { Planejar um programa de mudança de comportamento } \\
\text { de um cliente. }\end{array}$ & 3.17 \\
$\begin{array}{l}\text { Ser consultor de escolas sobre um novo programa de } \\
\text { prevenção }\end{array}$ & 3.02 \\
\hline $\begin{array}{l}\text { Dar informações sobre problemas psicológicos em um } \\
\text { programa de rádio }\end{array}$ & 1.82 \\
\hline Média geral & 2.96 \\
\hline
\end{tabular}

Na subescala de Atividades de "Perito em Psicologia Clínica" (Tabela 3), os itens de maior média, foram: organizar um programa de tratamento em hospital psiquiátrico (3,47 pontos) e delinear um novo método de tratamento para uma instituição de saúde mental (3,34 pontos), indicando maior interesse por atividades referentes à área de atuação clínica, repetindo mais uma vez os modelos existentes. O item de menor média foi "dar informações sobre problemas psicológicos em um programa de rádio" (1,82 pontos), talvez pelo fato de ser um atividade passível de ser criticada e pouco difundida no Brasil (Santos, 1992a). Vale pontuar que esta subescala possue no bojo de seus itens, uma atuação diferenciada do modelo tradicional de psicólogo e/ou Psicologia Clínica (Araújo e Murta, 1995), além de tarefas de planejamento muito semelhantes aos utilizados em pesquisa, o que foi igualmente menos pontuado anteriormente (Tabela 2).

Mais uma vez, na análise através do X2 não se rejeitou a hipótese nula, pois o índice de 3,99 não foi significativo $\left(X^{2}{ }_{c}=9,49\right.$; n.g.I. $=4$; n.sig. $\left.=0,05\right)$, encontrando mais uma vez um equilíbrio na pontuação dos itens desta subescala Tabela 3).

Tabela 4. Freqüência de respostas dos itens da subescala de Atividades em Estatística.

\begin{tabular}{l|c}
\hline \multicolumn{1}{c|}{ Item } & Média \\
\hline $\begin{array}{l}\text { Ler livro sobre um programa inovador quanto as } \\
\text { formas de pesquisa }\end{array}$ & 2,34 \\
\hline $\begin{array}{l}\text { Ajudar um colega a entender resultados estatísticos } \\
\text { confusos }\end{array}$ & 2,30 \\
\hline Aprender a um novo procedimento estatístico & 1,82 \\
\hline Escrever um programa estatístico & 1,54 \\
\hline Média geral & 2,00 \\
\hline
\end{tabular}

Referindo-se à subescala de "Atividades em Estatística" (Tabela 4), o item de maior média "ler livro sobre um programa inovador quanto às formas de pesquisa" (2,34 pontos) indica que os sujeitos não priorizam a busca por informações técnicas sobre estratégias de pesquisa ou base para análise estatística de seus dados. O segundo item de maior média "Ajudar um colega a entender 
resultados estatísticos confusos" (2,30 pontos) também apresenta pouco ou nenhum interesse significativo, fato que ocorre igualmente com outros itens desta subescala.

É interessante notar que o modelo quantitativo representado pela estatística, que é internacionalmente aceito, parece ser muito pouco atrativo para os sujeitos. Estes dados provavelmente são fruto de concepções errôneas sobre a natureza da ciência ou da Psicologia (Santos, 1992b e 1993), além de indicar um dos aspectos mais urgentes de revisão no ensino de Psicologia.

$\mathrm{O} \mathrm{X}^{2}$ observado nesta subescala foi de 2,81 , sendo que mais uma vez não se rejeitou a $\mathrm{H}_{\mathrm{o}}$ $\left(X^{2}=7,82\right.$; n.g.I. $=3$; n.sig. $\left.=0,05\right)$, repetindo o observado nas subescalas anteriores, onde não se observou nenhum item mais pontuado do que os demais.

Tabela 5. Freqüência de respostas dos itens da subescala de Atividades de Orientação e Avaliação da Produção Científica.

\begin{tabular}{l|c}
\hline \multicolumn{1}{c|}{ Item } & Média \\
\hline $\begin{array}{l}\text { Apresentar descobertas de pesquisa em uma } \\
\text { conferência }\end{array}$ & 3,08 \\
\hline $\begin{array}{l}\text { Supervisionar projetos de pesquisa de estudantes } \\
\text { Ser membro de comissão de avaliação de uma tese } \\
\text { ou dissertação }\end{array}$ & 2,60 \\
\hline Trabalhar como editor de uma revista científica & 1,91 \\
\hline Média geral & 2,54 \\
\hline
\end{tabular}

No tocante à sub-escala de "Atividades Científicas" (Tabela 5), o item "Apresentar descobertas de pesquisa em uma conferência" (3,08 pontos) obteve maior média, apresentando uma incongruência com os dados analisados anteriormente, que indicavam pouco interesse em coletar e analisar dados de pesquisa. Fica a questão de se verificar em outros estudos, as possíveis fontes destas descobertas científicas a serem "apresentadas" pelos sujeitos, uma vez que a atividade científica não parece ser a mais valorizada em suas práticas profissionais (Tabela 2), como indicam Santos (1993) e Rodrigues, Gums e Reis (1998).

Dentro dos itens desta subescala, o trabalho como editor de uma revista científica, atividade valorizada internacionalmente, recebeu a pontuação média igual a 1,91 pontos, sugerindo a não preocupação e motivação para o exercício profissional relacionado à construção da ciência psicológica, bem como o desconhecimento da importância desta atividade para o desenvolvimento da área.

De certo modo, estes dados podem ser considerados esperados, posto que a formação em Psicologia no Brasil pouco enfatiza e oportuniza a aprendizagem e desenvolvimento das habilidades científicas, repetindo o modelo tradicional de atuação, perpetuando o ciclo vicioso entre a identidade social da profissão e a formação fornecida aos futuros profissionais (Carvalho e Kavano, 1982).

Foi observado nesta subescala o $\mathrm{X}^{2}$ de 2,68, insuficiente mais uma vez para determinar a rejeição da $\mathrm{H}_{\mathrm{o}}\left(X^{2}{ }_{\mathrm{c}}=7,82\right.$; n.g.1.=4; n.sig.=0,05), pois não se observou nenhum item com escore maior do que os demais. 
Tabela 6. Freqüência de respostas dos itens da subescala de Atividades Docentes.

\begin{tabular}{l|c}
\hline \multicolumn{1}{c|}{ Item } & Média \\
\hline Formular uma teoria sobre o processo psicológico & 3,23 \\
\hline Escrever um livro científico para psicólogos & 2,47 \\
\hline $\begin{array}{l}\text { Desenvolver novas explicações sobre a boa aceitação } \\
\text { de estudos empíricos }\end{array}$ & 2,39 \\
\hline Média geral & 2.69 \\
\hline
\end{tabular}

No que diz respeito à subescala de "Atividades Docentes" (Tabela 6), "Formular uma teoria sobre processos psicológicos" obteve maior média, com 3,23 pontos. É interessante notar que os sujeitos indicaram esta atividade como a de maior interesse neste campo de atuação, mas nos itens anteriores relacionados à produção científica não pontuaram interesse (Tabelas 2, 4 e 5), sugerindo que os mesmos acreditam ser possível a produção científica exclusivamente da própria atuação clínica, resultante, talvez, de um processo meramente reflexivo, o que foi um caminho no início da Psicologia, mas hoje já não é mais suficiente e viável (Popper, 1975).

O item de menor pontuação média foi "Desenvolver novas explicações sobre a boa aceitação de estudos empíricos", com 2,39 pontos, indicando pouco interesse em atividades referentes ao desenvolvimento da Psicologia como ciência com tal característica. Estes dados podem ser também compreendidos à luz dos diversos estudos que apontam a grande influência e domínio da psicanálise no Brasil, pois este modelo rejeita não apenas o caráter empírico da ciência, mas também métodos quantitativos (Eysenck, 1993). Estudos como os conduzidos pelo C.F.P. em 1994 e 1988 apontam esta proposta como a mais freqüente entre os profissionais, o que pode ser considerado como uma medida indireta da influência de currículos e conteúdos programáticos.

Mais uma vez, na análise através do $\mathrm{X}^{2}$ não se rejeitou a hipótese nula, pois o índice de 1,97 não foi significativo $\left(X^{2}{ }_{\mathrm{c}}=5\right.$,99; n.g.1.=2; n.sig.=0,05), encontrando mais uma vez um equilíbrio na pontuação dos itens desta subescala.

Tabela 7. Freqüência de respostas dos itens da subescala de Atividades Psicométricas.

\begin{tabular}{l|l}
\hline \multicolumn{1}{c|}{ Item } & Média \\
\hline $\begin{array}{l}\text { Apresentar resultados de um caso clínico durante uma } \\
\text { conferência }\end{array}$ & 3,43 \\
\hline Aplicar um teste psicológico a um cliente & 2,93 \\
\hline Interpretar uma bateria de testes de um cliente & 2,93 \\
\hline Média geral & 2.96 \\
\hline
\end{tabular}

Na sub-escala "Atividades Psicométricas" (Tabela 7) o item mais pontuado foi "Apresentar resultados de um caso clínico durante uma conferencia" (3,43 pontos), voltado às questões anteriormente analisadas que dizem respeito ao alto interesse na área de atuação clínica e ao desconhecimento dos limites deste tipo de prática. Os demais itens que obtiveram a mesma pontuação média (2,93 pontos), abordam a utilização de testes psicológicos, indicando novamente pouca atenção em relação aos mesmos.

Mais uma vez, o item que mais se aproxima da prática clínica tradicional recebeu maior 
pontuação, o que reforça a predominância do modelo médico na preferência dos sujeitos.

Foi observado nesta subescala o $\mathrm{X}^{2}$ de 0,58 , insuficiente mais uma vez para determinar a rejeição da $H_{0}\left(X^{2}=5,99\right.$; n.g.1.=2; n.sig.=0,05), pois não se observou nenhum item com escore maior do que os demais.

Tabela 8. Síntese das freqüências médias observadas nas escalas do Inventário de Orientação Profissional Cientista-Prático.

\begin{tabular}{l|c}
\hline \multicolumn{1}{c|}{ Subescala } & Média \\
\hline Atividades Terapêuticas & 4,08 \\
\hline Atividades de Pesquisa & 3,09 \\
\hline Atividades de Perito em Psicologia Clínica & 2,96 \\
\hline Atividades em Estatística & 2,96 \\
\hline $\begin{array}{l}\text { Atividades de Orientação e Avaliação da Produção } \\
\text { Científica }\end{array}$ & 2,54 \\
\hline Atividades Docentes & 2,38 \\
\hline Atividades Psicométricas & 2,00 \\
\hline Média geral & 2,82 \\
\hline
\end{tabular}

No tocante à síntese das freqüências médias observadas nas escalas apresentadas na Tabela 8, "Atividades Terapêuticas" foi a subescala de maior média geral (4,08 pontos), o que vai de encontro ao esperado, pois indica o círculo vicioso entre a formação recebida e a identidade social da profissão (Carvalho e Kavano, 1982), o que demonstra um estágio de desenvolvimento atrasado da profissão (Campos, 1989; 1994). A escala que recebeu menor atenção foi "Atividades Psicométricas", tema comum na formação do psicólogo brasileiro (C.F.P., 1988), mas que não parece atrair os alunos da área.

Vale lembrar que o uso das medidas psicométricas é fundamental para o bom diagnóstico da problemática do cliente, do distúrbio de aprendizagem e condição intelectual da criança com dificuldades escolares ou mesmo na seleção de funcionários para uma empresa, o que indica ponto de relevância para estudo mais acurado sobre a temática. Além deste aspecto, deve-se considerar a importância das escalas relacionadas à produção científica e ao desenvolvimento da Psicologia como ciência paradigmática.

Na avaliação entre as médias das subescalas, o $l$ resultou em 4,61, insuficiente mais uma vez para determinar a rejeição da $\mathrm{H}_{0}\left(X^{2}{ }^{2}=12,59\right.$; n.g.l.=6; n.sig.=0,05), ou seja, na média não houve uma subescala com escore maior do que as demais, embora a análise qualitativa dos dados ao longo do trabalho reforce o predomínio da atividade clínica baseada no modelo tradicional.

\section{Considerações finais}

Este estudo relata a primeira experiência com o Inventário Cientista-Prático no Brasil. Os dados apontam para uma realidade sobejamente conhecida e relatada na literatura, refletindo, mais uma vez, o predomínio da área clínica.

Em. relação ao instrumento, há de se considerar que o mesmo se baseia no modelo norte- 
americano cientista-prático, que serve de base para a formação do psicólogo naquele país desde 1936 (Sanford, 1951). Além desta questão, o instrumento parece medir apenas duas dimensões: clínica e planejamento/ pesquisa em Psicologia, desconsiderando as áreas escolar, organizacional, esportiva, jurídica, entre outras.

Independente destas limitações, os dados relatam que a viabilidade do Inventário CientistaPrático é suficiente para justificar estudos posteriores de validação para a realidade brasileira, pois possibilitou identificar, ainda de forma limitada, a tendência de um grupo de alunos de Psicologia quanto à área de atuação.

Seria de muita valia a criação de instrumentos de orientação vocacional e profissional para estudantes de Psicologia, principalmente se considerar-se o grande número de sujeitos que abandonam a profissão (C.F.P., 1988 e 1994).

\section{Referências}

American Psychological Association. (I978). Careers in Psychology. Washington: APA.

Araújo, S. e Murta, S.G. (1995). Psicólogo: conceitos atribuídos por estudantes secundaristas e universitários goianienses. Anais da XXV Reunião Anual de Psicologia. Ribeirão Preto, p. 375.

Bastos, A.V.B. (1997). A escolha e o comportamento com a carreira: um estudo entre profissionais e estudantes de Administração. Revista de Administração, 32 (3): 28-39.

Blustein, D.L. (1995). Counseling psychology in the USA: historical perspective, current status and future directions. Cadernos de Consulta Psicológica, (10/11): 5-20.

Bonfim, E.M. (1993). Psicologia do Esporte e Psicologia Jurídica: atividades e sugestões para a formação profissional. Anais da XXIII Reunião Anual de Psicologia. Ribeirão Preto, p. 314.

Calejon, L.M.C. (1996). Manejo de crises e dificuldades adaptativas em universitários. Tese de Doutorado, IPUSP, São Paulo.

Campos, L.F.L. (1989). Supervisão clínica: um instrumento de avaliação do desempenho clínico. Dissertação de Mestrado PUC - Campinas (Psicologia Clínica).

. (1994). Supervisão em Psicologia Clínica: critérios, condutas e modelos de supervisão. Tese de Doutorado, IPUSP, São Paulo.

Campos, L.F.L.; Souza, K.C.C.; Catão, E.C. e Campos, P.R. (1996). Fatores motivacionais na escolha de abordagem teórica em Psicologia Clínica. Estudos de Psicologia, 13 (1): 41-54.

Carvalho, A.M.A. e Kavano, E. A. (I982). Justificativas de opção por área de trabalho em Psicologia: Uma análise da imagem da profissão em psicólogos recém-formados. Psicologia, 8(3):1-18.

Catão, E.C. (1999). Aconselhamento de Carreira: Uma Proposta de Instrumento para Área de Psicologia. Dissertação de Mestrado, Instituto de Psicologia. PGPE- PUC-Campinas.

Conselho Federal de Psicologia. (1988). Quem é o Psicólogo Brasileiro? São Paulo: Edicon.

(1994). Processo Constituinte repensando a Psicologia. Congresso Nacional Constituinte da Psicologia. Campos do Jordão: Autor.

Eysenck, H.J. (1993). Decadência e Queda do Império Freudiano. Rio de Janeiro: Ed. Civilização Brasileira.

Feixas, G. e Miró, M. T. B. (1993). Aproximaciones a Ia psicoterapia: uma introducción a los tratamientos psicológicos. Barcelona: Paidós.

Freitas, M.F.Q.; Menezes, LF. e Louzada, E.G. (I995). Tipo de conhecimento e esfera de atuação do profissional de Psicologia na opinião de estudantes da UFES. Anais da XXV Reunião Anual de Psicologia. Ribeirão Preto, p. 371.

Fuji, C.M. e Campos, L.F.L. (1997). Análise das categorias de preferências profissionais em estudantes de Psicologia. Anais do III Encontro de Iniciação Científica / V Encontro de Pesquisadores. Itatiba, p. 48

Goodyear, R.K e Bates, C.A. (1992). Counseling. Em: MC Alkin, ed. Encyclopedia of Educational Research. New York: Macmillan, p. 247-254. 
Guzzo, R.S.L. e Wechs]er, S.M. (1993). O psicólogo escolar no Brasil: padrões, prática e perspectivas. Em: R.S.L. Guzzo; L.S. Almeida e S.M Wechsler. Psicologia Escolar: padrões e práticas em países de língua espanhola e portuguesa. Campinas: Átomo.

Healy, C.C. (1992). Career counseling. Em: M.C. Alkin, ed. Encyclopedia of Educational Research. New York: Macmillan, p. 131-134.

Holland, J.I. (1978). La elección vocacional: teoria de las carreras. México: Trillas.

Leong, F. T.L. e Zachar, P. (1991). Development and validation of the Scientist-Practitioner Inventory for Psychology. Journal of Counseling Psychology, 38 (30): 331-341.

. (1992). A problem of personality: scientist and practitioner differences in Psychology. Journal of Personality, 60 (3): 665-677.

(1993). Presenting two brief versions of the Scientist-Practitioner Inventory. Journal of Career Assesment, 2 (1): 162-170.

Martins, C.R. (1978). Psicologia do comportamento vocacional: contribuição para o .estudo do comportamento vocacional. São Paulo: EPUIEDUSP.

Morato, H.T.P.; Costabile, C.; Eisenloar, M.G.; Simone, C. e Honora, K. (1993). Um serviço a serviço de alunos de Psicologia: a história de um projeto. Boletim de Psicologia, XLIII (88/89): 95-110.

Osipow, S.H. (1990). Careers: research and personal or how I think an individuals personal and career life interwine: a personal example.The Counseling Psychologist, 18 (2): 338-347.

Pacheco, AL.P.B.; Mascarenhas, M.L. e Magioli, AM. (1998). Escolhendo a profissão de psicólogo. Anais da XXVIII Reunião Anual de Psicologia. Ribeirão Preto, p. 181.

Passarelli, L.B. (1991). Uma crítica ao conceito de escolha profissional: um estudo exploratório na carreira profissional de informática. Dissertação de Mestrado, IPUSP, São Paulo.

Pfromm Netto, S. (1992). Pesquisa científica em Psicologia: lacunas, fragilidades e desafios nos anos 90. Cadernos de Psicologia, 1 (novembro), 1: 107-126.

Popper, K.R. (1975). A lógica da pesquisa científica. São Pualo: Cultrix/EDUSP.

Rodrigues, M.M.P.; Gums, C. e Reis, C.T. (1998). Iniciação científica, formação e atuação profissional do psicólogo. Anais da XXV]]I Reunião Anual de Psicologia. Ribeirão Preto, p. 56.

Sanford, F .H. (1951). Annual Report of Executive Secretary. American Psychologist, 6: 664-670.

Santos, M.A. (1992a). Áreas de atuação em Psicologia: a (de)construção da imagem social da profissão e da identidade do Psicólogo. Anais da XXII Reunião Anual de Psicologia. Ribeirão Preto, p. 58. (1992b). O que é Psicologia?: representação social da profissão entre alunos do curso de formação. Anais da XXII Reunião Anual de Psicologia. Ribeirão Preto, p. 57. . (1993). Representação gráfica da atuação profissional em Psicologia. Anais da XXIII Reunião Anual de Psicologia. Ribeirão Preto, p. 97.

Staats, AW. (1987). Unified Positivism: Philosofy for Unimic Psychology. In Baker, J.W.; Hayland, M.E.; Van Rappord, H.L. e Staats, AW.- Current Issues in Teorical Psychology. North Holland: Elsever Science $\mathrm{Pu}$.

Teixeira, M.AP. e Gomes, W.B. (1998). Mudança profissional: uma abordagem fenomenológica. Anais da XXVIII Reunião de Psicologia. Ribeirão Preto, p. 131.

Witter, G.P. (1996). Pesquisa científica e nível de significância. Estudos de Psicologia, 13 (1): 55-63. 